\title{
Student Practice In 3D Design and Printing for Promoting Analytical and Applied Mathematical Thinking Skills
}

\author{
https://doi.org/10.3991/ijep.v11i3.19893 \\ Laura Levin $\left.{ }^{\bowtie}\right)$, Igor Verner \\ Technion - Israel Institute of Technology, Haifa, Israel \\ laura-lecampus.technion.ac.il
}

\begin{abstract}
The educational literature emphasises the key role of analytical thinking (AT) and applied mathematical skills (AMS) in solving engineering problems and calls to nurture these skills in school STEM education. This study proposes and explores a strategy for fostering AT and AMS among middle school students and prospective teachers through practice in digital design and 3D printing. The study involved 32 seventh grade students and five prospective teachers of technology. Both groups learned a 10-hour workshop, "Make a spinning-top." The participants designed spinning-tops that can fit into a Kinder Surprise egg and analysed their geometric and mechanical properties. We collected data from students' worksheets, their designed artefacts, and in-class discussions. The results indicated that the assignment prompted the participants to apply AT and AMS. School students designed complex models, inquired into their geometry, and verified their designs through 3D printing. The worksheets were found to be a useful tool to frame and guide students' thinking in the design tasks and the creation and testing of mathematical models. For the prospective teachers, the workshop, accompanied by lectures on the methodology of experiential learning, enabled them to implement mathematical solutions in designs and develop instructional units on the subject.
\end{abstract}

Keywords - Analytical thinking, Applied mathematical skills, 3D printing, middle-school education, 3D design

\section{Introduction}

Affordable desktop 3D printers have become accessible in the last decade, and schools are beginning to adopt this technology with an increasingly positive impact $[1,2]$. Learning environments that incorporate 3D design and printing (3DP) foster students' design thinking and problem-solving skills while creating artefacts. Training students to cope with this advanced digital technology prepares them for life in the current era of digital transformation [3].

One of the main approaches to integrating 3D printing in school education is the learning-by-design approach [4]. According to this approach, learning occurs when students are engaged in a design challenge. Through the design challenge, they gather 
relevant information, make inferences, analyse and test their design, explain their design decisions, and iterate toward success $[5,6]$. Previous studies have indicated that this approach may enhance students' mathematical and engineering understanding [7]. Ford and Minshall [1] have examined the integration of 3D printing in middle school STEM curricula. As indicated, through the design and making of physical artefacts, students concretised concepts and constructed knowledge. In this constructionist learning, the created artefacts served as "objects-tothink-with" [8].

However, the lack of teaching methodologies and teacher training in 3DP technopedagogy, as well as cultural, institutional, and financial hurdles, hinder the integration of 3DP in school practice [1]. The research and development of such methodologies have recently started.

There is a broad consensus that school education should prepare students for the challenges of the fast-paced, changing world. To this end, higher-order thinking skills and technological literacy have been deemed to be important. Teaching strategies for developing thinking skills in different contexts are widely discussed in the literature. In our research, we focus on developing two of these skills, namely, analytical thinking and applied mathematical skills.

The new standards for school mathematics and science education $[9,10]$ refer to analytical thinking as the target skill necessary to logically and systematically solve complex problems by their decomposition. World Economic Forum [11] noted analytical thinking first in the top skills demanded from the workforce by the modern job market. The education standards refer to the applied mathematical skills needed to understand ill-defined problems, collect and quantify relevant data, and construct and inquire mathematical models $[9,10]$. These skills are tested by the international student assessment program PISA [12].

Following the learning-by-design approach, our study explores the integration of learning activities in digital design and 3D printing as a strategy to foster analytical thinking and applied mathematical skills among middle school students and prospective teachers. In this paper, we propose and explore an approach to the development of AT and AMS by engaging students in the design and creation of 3D printed artefacts and their mathematical analysis. We examined and described the characteristics of learning assignments and strategies that promote thinking development. We also analysed prospective teachers' reflections on their learning experience in the workshop. Involving in this study university students who are prospective teachers provided us an additional perspective to examine the proposed approach. This article is an extended and revised version of an article published in EDUCON 2020 [13].

\section{Analytical and Applied Mathematical Skills}

Analytical thinking (AT) is defined as the mental ability to break an object or idea into parts, identify, and classify its different components [14]. This ability includes finding causal relationships among the components and evaluating the usefulness of 
this analysis for decision-making and problem-solving. The dual processing theory characterises the cognitive mechanisms of AT and provides the basis for the development of strategies for its development. According to the theory, two complementary processes occur, intuitive or heuristic thinking (named System 1) and analytical thinking (System 2) [15]. System 1 (S1) constructs mental models of the situation when facing a cognitive task and provides intuitive responses. System 2 (S2) may or may not intervene to control, revise analytically, and replace the intuitive response provided by S1. Appropriate learning activities aimed to foster S1 and S2 processes, and their interaction may help improve problem-solving and decisionmaking performances [16, 17].

Applied mathematical skills (AMS) are a synergistic combination of mathematical skills and the ability to solve practical problems by creating and exploring their mathematical models. AMS are in high demand in the modern job market [18]. These skills include understanding the real-world problem, constructing a mathematical model, finding a mathematical solution, and interpreting the solution in terms of the real-world problem. The theory of situated cognition characterises the mechanisms of learning in a real-world context [19] .

AT and AMS are crucial for engineers who apply them along the design process to analyse requirements, solutions, and evaluation of the products [20]. These skills are equally necessary for many other areas of professional and everyday activities. Despite this, school education does not pay due attention to their development [21].

\section{Developing Students' Thinking Skills}

Educators conceive learning thinking skills as a process of transformation from unskilled to skilled thinking, which "implements thinking means in a fast and precise way" [22, p. 1848]. Skilled thinking is based on past experience in the learning subject and adequate thinking patterns and procedures [23, 24]. As noted by Beyer, researchers state that although thinking develops naturally and sporadically, skilled thinking development requires more than just practical experience. It also requires systematic and intentional educational intervention.

Researchers recommend introducing a new thinking skill through a direct approach, presenting procedures for the application of the skill itself. In our case, to promote analytical thinking in the context of problem-solving in 3DP, it is recommended to devote special attention to such thinking procedures as identifying the components of the problem, finding causal relationships among the components, and evaluating the reliability and usefulness of information regarding the problem. Similarly, to foster applied mathematical thinking, such skills as the presentation of step-by-step procedures for interpreting and making sense of the real-life problem, simplifying it, identifying the underlying mathematical problem, solving, verifying, and translating it back to real-life terms will be necessary.

Mastering a new thinking skill is an arduous and challenging task that demands cognitive efforts. Therefore, when learning to apply the skill, it is recommended to 
minimise distractions and then engage students in thinking activities in different contexts.

In particular, to foster analytical thinking and applied mathematical skills, it is recommended to present the learning activities that integrate 3DP after the students mastered the 3D modelling tools. However, as Resnick stated, reasoning "cannot be done in the abstract, one must reason on something" [25, p. 36]. In order to promote students' thinking, a learning environment should provide ample opportunities for students to actively engage in thinking activities in different contexts [26, 27]. According to the infusion approach proposed by Swartz and Parks, thinking skills are not taught as a subject in itself. Teaching the skill should be embedded in a subjectmatter curriculum in an integrated way [27, 28]. Moreover, while practising the thinking skill as part of a subject-matter learning activity, students learn what is considered skilled thinking in the discipline. When solving applied mathematical problems, the process of mathematisation is of critical importance. In the context of 3DP, the learner's attention focuses on the artefact being created as an "object-tothink-with" [8]. Papert stated that experiential learning practice in technological environments can help students develop concrete representations of abstract concepts and ideas. Similarly, practice in a 3D design and printing environment, which is a rich source of interesting and challenging mathematical problems, can facilitate the learning of engineering and mathematics concepts. In solving applied mathematical problems, the creation of artefacts drives students to develop ideas and discuss them with peers.

Researchers recommend concrete techniques for teaching thinking skills. These techniques aim to directly introduce the thinking processes and make them visible and explicit. One of these techniques is modelling, in which the teacher presents to the students her/his own way of thinking when solving a problem [29]. Solving 3D design and printing problems in groups can provide opportunities for using this technique. Students can learn from their peers how they analyse the task, approach the design problem, and become aware of different mental processes that otherwise remain hidden.

Another technique is the metacognitive reflection [24, 30, 31], where students reflect upon their way of reasoning. Teachers can foster students thinking by using metacognitive prompts presented as questions in worksheets or during class discussions and workgroup. Whimbey and Lochhead [32] pointed out that thinking aloud during reasoning or problem-solving forces the thinker to be more careful, aware and thorough in analysing ideas. Students may feel awkward and strange to think aloud while working alone. However, when they work in groups on design problems, thinking aloud is a natural way to collaborate and communicate with peers. During the process of $3 \mathrm{D}$ design and printing, students can reflect, verbalise and explain their design decisions. The designed objects not only constitute objects to think with but also objects to talk about.

Several teaching routines for guiding and supporting thinking skill practice have been identified [24]. The first routine is scaffolding, in which the teacher frames the students thinking, providing explicit guidance. The second one, cueing, provides students with prompts that help them along the thinking process without providing a 
precise answer. The regular use of the language of thinking in everyday classroom discourse is also widely recommended. When students are involved in 3D design and printing problems aimed at fostering analytical thinking, the language should include identification of geometrical shapes, dimensions and problem constraints, finding relationships between design and constraints and evaluation of the solution against the requirements. Other recommended teaching routines are coaching and providing feedback. In this study, we implemented several teaching routines and techniques to promote students' thinking.

\section{The Learning Activities}

In our study, we developed and evaluated a workshop, "Make a spinning-top." Learning activities in the workshop were designed following the theory of situated cognition [19]. According to this theory, learning is tightly coupled with the context, the activity, the artefacts, and the social interactions taking place in the learning environment. We aimed to focus the learning activities on fostering analytical thinking and applied mathematical skills. To this end, we formulated assignments as ill-defined problems in which, in order to understand and solve them, students needed to apply both intuition, analytical thinking, and mathematical modelling [33, 34]. The modelling process included mathematising real-world situations, building a mathematical model, and validating the mathematical solution in the real-world context [35].

In the workshop assignment, devised following the above principles, we asked the participants to act as toy designers contracted by a local candy brand. They were prompted to design and 3D print a spinning-top toy that can fit into a Kinder Surprise egg and spins as long as possible. After the design and 3D printing of the spinningtop, the participants were requested to present their solutions and explain their design considerations and mathematical analysis. Since we did not specify the surprise egg dimensions and the spinning-top geometry, the participants had to find the relevant information by themselves and build a mathematical model to analyse the spinningtop.

\section{$5 \quad$ The Study}

The aim of this study was to develop, implement, and evaluate our approach to fostering analytical thinking of students by engaging them in mathematical analysis, design, and creation of $3 \mathrm{D}$ printed artefacts. We identified and characterised the features of the assignment that prompted the learners to apply AT and AMS. We also analysed prospective teachers' reflections on the learning experience.

The study involved two groups of participants: 32 seventh grade students aged 1314 and five prospective teachers. All the middle school students belonged to the same class and studied mathematics at an advanced level in a middle school located in the central area of Israel. The prospective teachers were students of the Technion Faculty 
of Education in Science and Technology, majoring in technology education. The majority of them held engineering degrees.

The study with prospective teachers took place during the fall semester of the 2018-2019 academic year in the framework of the course "Methods of teaching technology - mechanics." The workshop for middle-school students was conducted as part of an in-school enrichment program for highly motivated but not necessarily high-achieving students.

\subsection{The workshop}

The 10-hour workshop "Make a spinning-top" was conducted to both groups. The workshop consisted of a two-hour introduction to 3D printing and eight hours of experiential learning sessions. No prior knowledge was required to participate in the workshop. The introductory lesson exposed the participants to 3D printing, its history, actual uses and perceived potential. We demonstrated how the printer works and how to design objects using Tinkercad software and print them using a MakerBot 3D printer. At the last part of the introductory lesson, the participants performed a basic exercise to get acquainted with the Tinkercad software and 3D design and printing process. In this exercise, the students designed and 3D printed simple artefacts by selecting and combining basic shapes available in Tinkercad, changing their dimensions and spatial orientation.

The eight hours of experiential learning sessions were devoted to designing, 3D printing, and analysis of a spinning-top that can fit into a Kinder Surprise egg and spins as long as possible. The workshop was given in two versions, adapted to prospective teachers and middle-school students. The introductory lessons were similar for both groups, but the experiential learning sessions were organised in different manners, as described below and in Table 1.

Table 1. Outlines of the two workshops

\begin{tabular}{|c|l|c|c|}
\hline \multicolumn{2}{|l|}{ Workshop for prospective teachers } & \multicolumn{1}{c|}{ Workshop for 7th-grade students } \\
\hline Duration & \multicolumn{1}{|c|}{ Activity } & Duration & \multicolumn{1}{|c|}{ Activity } \\
\hline 2hs. & Introductory lesson to 3DP & 2hs. & $\begin{array}{l}\text { Introductory lesson to } \\
\text { 3DP }\end{array}$ \\
\hline 2hs. & $\begin{array}{l}\text { Design of a spinning-top surprise toy using } \\
\text { Tinkercad }\end{array}$ & 4hs. & $\begin{array}{l}\text { - Design of a spinning-top } \\
\text { surprise toy using } \\
\text { the design in worksheets, } \\
\text { 3D printing and re-design } \\
\text { of the top }\end{array}$ \\
\hline Homework & 3D printing and re-design of the top & Homework & 3D printing \\
\hline 2hs. & $\begin{array}{l}\text { Presentations of the created tops and design } \\
\text { considerations }\end{array}$ & $\begin{array}{l}\text { Worksheets peer reviews, } \\
\text { Design of an asymmetric spinning-top } \\
\text { solutions and designs, } \\
\text { presentations }\end{array}$ \\
\hline Homework & $\begin{array}{l}\text { 3D printing and re-design of the top } \\
\text { 2hs. }\end{array}$ & $\begin{array}{l}\text { Presentations of the tops, design considerations and } \\
\text { mathematical models }\end{array}$ & \\
\hline
\end{tabular}


In the course for prospective teachers, the two hours of introductory lesson and the eight hours of experiential learning sessions were given in parallel with lectures on learning theories applied in technology education. The lectures presented the principles of mathematical modelling [33], followed by an example explicitly showing mathematical reasoning at each step of the mathematical modelling process. The experiential learning practice was organised in four two-hour sessions. In the first session, the prospective teachers (teacher-students) designed and 3D printed spinningtops. The teacher-students worked in pairs and were asked to think aloud during the design process, following the steps of the mathematical modelling process presented in the lectures. In the second session, they presented their design considerations, including analysis of the designed spinning-tops' geometric and mechanical properties. In the third session, the teacher-students were challenged with an upgraded assignment to create an asymmetric spinning-top and base its design on mathematical analysis. In the fourth session, the teacher-students presented their spinning-tops and the results of their mathematical analysis, focusing on the top's dynamic balance and precession. After the workshop, the prospective teachers submitted written reflections on their learning experience in the workshop. Examples of spinning-top designs and their mathematical analysis performed by the prospective teachers are presented in Fig. 1.

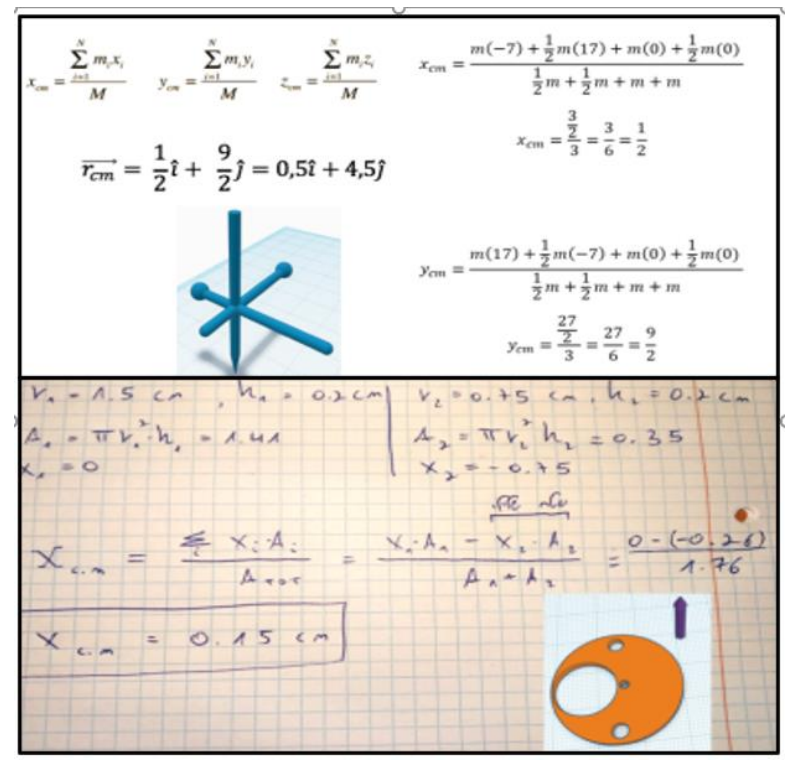

Fig. 1. Prospective teachers spinning-top designs and their mathematical analysis

In the middle-school class, the workshop was delivered by the researcher while the mathematics teacher accompanied the sessions and provided support to the students. The students worked in groups of four, designing their spinning-tops and discussing their ideas. In contrast to the pairs as in the teacher-students workshop, the groups of four students enabled to encourage students discourse and thinking aloud practice and 
reduce the number of groups. The design activity was guided by a worksheet where the students wrote down their design considerations and mathematical analysis. The worksheet provided scaffolding and cues. It also prompted the students to analytically think about the spinning-top as a structure consisted of three-dimensional shapes, calculate or estimate its maximal possible size and surface area, and solve equations to determine geometric parameters.

The experiential learning practice was organised as two four-hour sessions, according to the schedule given by the school administration. In the first session, the students designed the spinning-tops while being guided by the worksheets. They 3D printed their designs, tested the produced spinning-tops, and re-designed them if necessary. The 3D printing of students' products took place mostly between the workshop sessions. In the second four-hour session, the students were asked to review their peers' worksheets and give comments on the documented designs and mathematical analysis. This assignment aimed to provide students with feedback on their designs and expose them to their peers' designs and analyses. Next, the students engaged in a whole-class discussion, presenting alternative solutions and design considerations based on mathematical analysis. Through the review and discussion, the students had the opportunity to explicitly see others' ways of thinking when performing the task and learn from them. Finally, each group presented the designed spinning-top, and a competition was held, looking for the spinning-top that spins the longest. Examples of sketches, designs, and artefacts developed by the students are presented in Fig. 2.

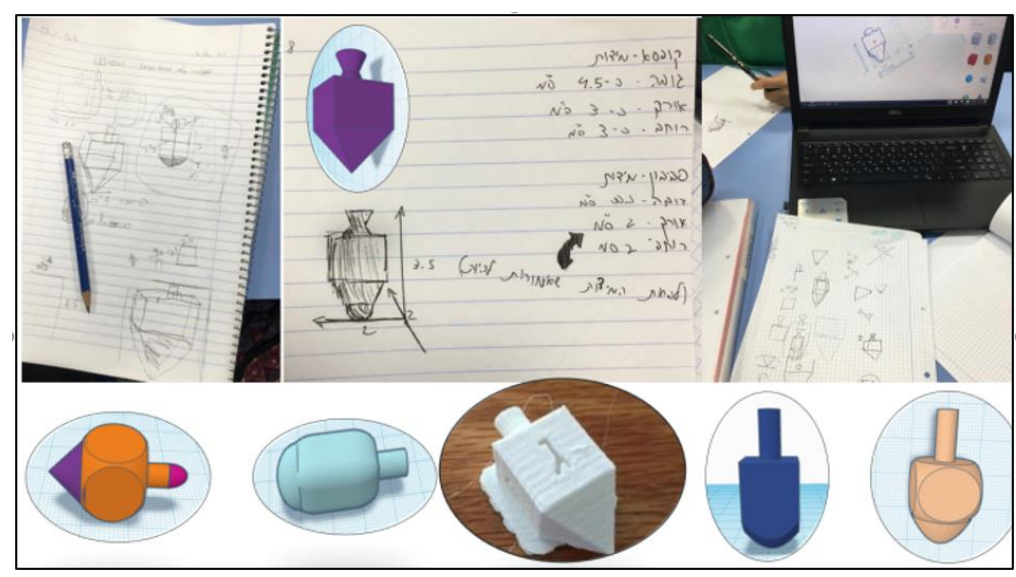

Fig. 2. Middle school students' sketches, designs and artefacts.

\subsection{Data collection and analysis}

Through observation of activities of school students and prospective teachers (teacher-students), we identified cases in which they applied AT and AMS. We analysed the cases using performance data from the students' worksheets, sketches, Tinkercad designs, and 3D printed artefacts. Regarding the teacher-students, we 
analysed applications of AT and AMS manifested in their presentations, task reports, and answers to the post-workshop questionnaire.

Based on the literature [33, 36-39], we defined patterns of analytical thinking and applied mathematics skills, denoted them by codes, and used the codes for the analysis of the collected manifestations of AT and AMS. The defined codes for analytical thinking were:

- AT1: Identifying and classifying different components of an object.

- AT2: Finding causal relationships among the components.

- AT3: Evaluating the usefulness and reliability of information for making decisions and solving problems.

The codes for applied mathematical skills were:

- AMS1: Understanding real-world problems.

- AMS2: Using mathematical language to define problems, communicate ideas and solutions.

- AMS3: Organising, analysing, and interpreting numerical data to determine relationships among factors.

\section{$6 \quad$ Findings}

In this study, we developed and evaluated an approach to foster AT and AMS through learning activities in 3DP. We designed assignments and evaluated learning in two versions of the workshop given to middle-school students and prospective teachers.

The first task for prospective teachers was to make a spinning-top that can fit into a Kinder Surprise egg. Although the task was relatively easy, some of them did not manage to create a spinning-top small enough to fit into the case, and others did not spin. The mathematical models and explanations given by the prospective teachers were at a relatively basic level, and they mostly referred to the moment of inertia. We conjectured that the task was too open in terms of the expected mathematical analysis. For the next task, we assigned the students to re-design their models and make asymmetric spinning-tops. This time, the asymmetry constraint forced the students to refer to the centre of mass and applied mathematical analysis to calculate it, as shown in Fig. 1. Their previous experience led them to consider if the designed model can be printed and if the amount and distribution of mass will allow spinning.

After the workshop, the prospective teachers submitted written reflections on their learning experience in the workshop. Below are two excerpts, exemplifying the prospective teachers' reflections on using analytical thinking and applied mathematical thinking during the learning process:

" $3 D$ printing made it possible to examine in practice the theoretical models (physics and math formulas) and the actual model to check whether there was a match." 
"When we built the spinning-top we experimented with the following learning skills: creative thinking (brainstorming, creating, designing, and imagining), critical thinking (analysing, arguing, comparing, and evaluating), and mathematical thinking (figuring out to use the centre of mass, thinking about geometry, physics, vectors and strengths)".

The reflections indicated that the prospective teachers recognised the potential of using 3DP to examine in practice the learned concepts.

In the middle-school students' workshop, we used worksheets to scaffold the design process with thinking prompts and questions. The task was openly defined to allow for a variety of solutions and designs. The students were highly involved in the activity. They collaborated to design their spinning-tops and discussed plausible solutions using mathematical language. The 3D printing of the spinning-tops allowed them to test their ideas and improve their designs. The students drew sketches, chose geometrical forms for their designs, measured the Kinder egg container, and defined the spinning-top dimensions (Fig. 2). Indications of analytical and applied mathematical thinking were observed during the activity. We found that the worksheet prompted and guided the students toward using AT and AMS.

When seeing the worksheet questions "What is the largest spinning-top that can be inserted into the surprise egg?" and "How did you calculate the dimensions?", one of the students showed to his mathematics teacher a sketch of a square circumscribed by a circle and asked:

"How can we find the largest square that can be inserted into the diameter of a Kinder egg?"

In this example, the student understood the real-world problem (AMS1). He identified the components of the problem and simplified them to build a mathematical model: a circle for the circumference of the surprise egg and a square for the cubed body of the designed spinning-top (AT1). He also communicated the problem with his teacher using mathematical language and representations (AMS2). In response, the teacher explained to him the Pythagorean theorem (which has not yet been taught in the class) (AMS2, AT3). In the next session, the student presented the solution to the class based on the Pythagorean theorem (AT2, AMS2, AMS3).

In other cases, we observed indications of mathematical and design discourse (AMS2, AT3). When working on the worksheet prompt "Design the spinning-top. What are the dimensions of each body compounding the spinning-top? Describe as much as you can", two students had the following conversation:

Student A: "To define the size of the spinning-top, we first must calculate the volume of the cylinder [the Kinder Egg]. What is the formula of the volume of a cylinder? I do not remember"

Student B: "Look it up on Google."

After finding the volume formula:

Student A: "Ahhhh, it is better not to use the volume, but the diameter of the Kinder egg"

The above dialogue exemplifies the discourse observed during the workshops. The dialogue was in mathematical language. The students verified and revised their 
intuitive solutions using analytical thinking and evaluated the information needed for solving the problem.

The summary of the findings received in our study is presented below.

- 3D design and printing practices, such as those explored in our study, can prompt learning processes that are relevant for middle school mathematics classes and expose the students to modern digital technology. Posing proper design assignments and learning frameworks can prompt analytical thinking and applied mathematical problem-solving.

- We identified specific features of the Kinder Surprise egg assignment that stimulated AT and AMS in the students. The assignment was familiar to the students from real life. It was complex and required the use of 3DP technologies. The design problem was open and ill-defined, requiring the students to think analytically on how to make the spinning-top and apply mathematical reasoning in order to determine its shape and dimension so that to fit it into the given egg. The level of the design problem was adapted to the level of learners. While the middle school students designed a symmetric spinning-top, the prospective teachers had to design an asymmetric top, which demanded of them to analyse its geometrical and mechanical properties.

- The assignment worksheet served as a useful tool to scaffold the middle school students in learning through the 3DP practice. The worksheets included questions that invited the students to systematically observe the components of the designed spinning-top and mathematically analyse their characteristics. In the worksheets, the students systematically documented the problems they solved along the 3DP process, including the concepts and theorems (e.g., the Pythagorean Theorem) that they used to calculate the geometric parameters of the models.

- Commending the contribution of the 3DP workshop, the prospective teachers evaluated the opportunity to examine in practice the basic concepts of dynamics, implement mathematical solutions in designs, materialise the designs into physical artefacts, and develop instructional units on the subject.

\section{$7 \quad$ Discussion and Conclusion}

Preparing students for life in the era of digital transformation is an important mission of modern education. The implementation of this mission requires the provision of digital literacy, of which computer-aided design and 3D printing skills are an integral part. In this paper, we showed how to introduce a workshop in design and 3D printing in middle school and teacher education, in order to foster the development of analytical thinking and applied mathematical skills. We integrated learning thinking skills through 3D design problem-solving in a middle school mathematics class and a technology education course.

We have found that 3DP activities can foster analytical thinking and applied mathematical skills. This finding is in line with results of previous studies in designbased learning as a way to teach mathematics [6, 40]. In our case, we use designbased learning to teach how to apply mathematics to solve real-life problems. Our 
study adds to prior work by determining the characteristics of 3DP assignments that promote analytical and applied mathematical thinking skills. The use of open-ended assignments for promoting thinking skills was recommended in the literature [41, 42]. Our study indicated that adding appropriate constraints to such an open-ended assignment may promote thorough mathematical modelling and, this way, lead to the development of analytical thinking and applied mathematical skills. In our workshop for prospective teachers, the asymmetry constraint was the drive that inspired the teacher-students to use analytical and applied mathematical skills in the 3DP assignment. Similarly, the fitting into a surprise egg constraint provided middleschool students with a challenge not only to represent the real-life situation mathematically but also kept them away from proposing an intuitive solution to the design task.

Following the literature recommendations, we encouraged the school students to think aloud and provided them with the opportunities to share and discuss their solutions with their peers. These practices not only contributed to fostering thinking but also enabled us to follow students' thinking processes. In line with previous studies on teaching thinking skills [30,43, 44], we found that worksheets with prompting instructions, questions and cues can serve to scaffold middle-school students' thinking and induce metacognitive reflection.

To prepare students for the challenges of the fast-paced, changing world, we have to impart prospective teachers' competencies for teaching with digital technology. The prospective teachers that participated in this study recognised the potential of 3DP to promote learning as well as thinking skills. Together with other researchers dealing with $3 \mathrm{D}$ printing in education [1], we claim that $3 \mathrm{D}$ printing the designed artefacts can help to visualise the learned concepts and test the solution, and provide added-value to the learning-by-design experience. In our study, the 3D artefact served as an object to think with as well as an object to relate to while thinking aloud during the design process.

The positive results of the implementation of our approach in one middle-school class and a teacher education course prompt us to continue and deepen the study. We are interested in exploring more explicit use of thinking vocabulary, coaching, and feedback in different 3DP assignments. Further work should consider a more extended intervention and a broader age range. Also, future investigation is needed to explore ways for a more thorough evaluation of learning outcomes, and particularly the gain in analytical thinking and applied mathematical skills.

\section{Acknowledgement}

Our research is supported by the grants of PTC Corp. and the Technion Gordon Center for Systems Engineering. 


\section{$9 \quad$ References}

[1] S. Ford and T. Minshall, "Where and how 3D printing is used in teaching and education," Additive Manufacturing, vol. 25, pp. 131-150, 2019. https://doi.org/10.1016/j.addma. 2018.10.028

[2] A. Pikkarainen and H. Piili, "Implementing 3D printing education through technical pedagogy and curriculum development," International Journal of Engineering Pedagogy, vol. 10, no. 6, pp. 95-119, 2020. https://doi.org/10.3991/ijep.v10i6.14859

[3] A. Stansell and T. Tyler-Wood, "Digital fabrication for STEM projects: A middle school example," in Proceedings - IEEE 16th International Conference on Advanced Learning Technologies, ICALT 2016, 2016, pp. 483-485.https://doi.org/10.1109/icalt.2016.44

[4] J. L. Kolodner, J. Gray, and B. B. Fasse, "Promoting transfer through case-based reasoning: Rituals and practices in learning by design classrooms," Cognitive Science Quarterly, vol. 3, pp. 183-232, 2003.

[5] I. Verner and A. Merksamer, "Digital design and 3D printing in technology teacher education," Procedia CIRP, vol. 36, pp. 182-186, 2015. https://doi.org/10.1016/j. procir.2015.08.041

[6] R. Mayes and B. Gallant, "Interdisciplinary STEM through engineering design-based reasoning," International Journal of Engineering Pedagogy, vol. 8, no. 3, pp. 60-68, 2018.

[7] G. Bull, J. Chiu, R. Berry, H. Lipson, and C. Xie, “Advancing children's engineering through desktop manufacturing," in Handbook of Research on Educational Communications and Technology, 4th ed., J. M. Spector, M. D. Merrill, J. Elen, and M. J. Bishop, Eds. New York: Springer, 2014, pp. 675-688. https://doi.org/10.1007/978-1-46143185-5_54

[8] S. Papert, "Mindstorms: Computers, Children, and Powerful Ideas," NY Basic Books, 1980.

[9] Common Core State Standards Initiative, "Common Core State Standards for Mathematics," 2010. https://doi.org/10.1037/e509442010-006

[10] NGSS Lead States, Next Generation Science Standards: For States, By States. 2013.

[11] World Economic Forum, "The Future of Jobs Report 2018," Geneva, 2018.

[12] OECD, "What is PISA?" in PISA 2018 Assessment and Analytical Framework, Paris: OECD Publishing, 2019, pp. 11-19. https://doi.org/10.1787/2c7c311d-en

[13] L. Levin and I. Verner, "Fostering students' analytical thinking and applied mathematical skills through 3D design and printing," in Proc. IEEE Global Engineering Education Conference, EDUCON, Porto, Portugal, 2020, pp. 145-149.https://doi.org/10.1109/ educon45650.2020.9125358

[14] K. Koyimah, W. Widodo, N. Suprapto and B. Kurni, "Effectiveness of interactive microcontroller-based speed sensors to improve students' analytic thinking skills," International Journal of Online and Biomedical Engineering, vol. 16, no. 9, pp. 173-182, 2020. https://doi.org/10.3991/ijoe.v16i09.15185

[15] D. Moore, J. Sauder, and Y. Jin, “A dual-process analysis of design idea generation," in Proceedings of the ASME Design Engineering Technical Conference, 2014.

[16] U. Leron and O. Hazzan, "Intuitive vs analytical thinking: four perspectives," Educational Studies in Mathematics, vol. 71, no. 3, pp. 263-278, 2009. https://doi.org/10.1007/s10649$\underline{008-9175-8}$

[17] A. Baghaei Lakeh and N. Ghaffarzadegan, "The dual-process theory and understanding of stocks and flows," System Dynamics Review, vol. 32, pp. 309-331, 2016. https://doi.org/10.1002/sdr.1566 
[18] OECD, "Innovating Education and Educating for Innovation: The Power of Digital Technologies and Skills," Paris, 2016.

[19] J. S. Brown, A. Collins, and P. Duguid, "Situated cognition and the culture of learning," Educational Researcher, vol. 18, no. 1, pp. 32-42, 1989.https://doi.org/10. 3102/0013189x018001032

[20] C. A. Talib, F. Aliyu, A. M. bin A. Malik, and K. H. Siang, "Enhancing students' reasoning skills in engineering and technology through game-based learning," International Journal of Emerging Technologies in Learning, vol. 14, no. 24, pp. 69-80, 2019. https://doi.org/10.3991/ijet.v14i24.12117

[21] O. V. Shipulina, D. H. Smith, and P. Liljedahl, "Bringing reality into calculus classrooms: Mathematizing a real-life problem simulated in a virtual environment," International Journal of Engineering Pedagogy, vol. 3, no. 1, pp. 29-35, 2013. https://doi.org/10.3991/ ijep.v3i1.2337

[22] Y. Harpaz, "Approaches to teaching thinking: Toward a conceptual mapping of the field," Teachers College Record, vol. 109, no. 8, pp. 1845-1874, Aug. 2007

[23] N. C. Boreham, "The dangerous practice of thinking," Medical Education, vol. 28, no. 3, pp. 172-179, 1994.

[24] B. K. Beyer, "What research tells us about teaching thinking skills," The Social Studies, vol. 99, no. 5, pp. 223-232, 2008. https://doi.org/10.3200/tsss.99.5.223-232

[25] L. B. Resnick, Education and Learning to Think. Washington: National Academy Press, 1987.

[26] P. Liljedahl, "Building thinking classrooms: Conditions for problem-solving," in Posing and Solving Mathematical Problems: Advances and new perspectives, P. Felmer, J. Kilpatrick, and E. Pekhonen, Eds. New York: Springer, 2016, pp. 361-386. https://doi.org/10.1007/978-3-319-28023-3 21

[27] A. Zohar and N. Schwartzer, "Assessing teachers' pedagogical knowledge in the context of teaching higher-order thinking," International Journal of Science Education, vol. 27, no. 13, pp. 1595-1620, Jan. 2005. https://doi.org/10.1080/09500690500186592

[28] E. Aizikovitsh and M. Amit, "Evaluating an infusion approach to the teaching of critical thinking skills through mathematics," Procedia - Social and Behavioral Sciences, vol. 2, no. 2, pp. 3818-3822, 2010. https://doi.org/10.1016/j.sbspro. 2010.03.596

[29] D. Wedelin and T. Adawi, "Teaching mathematical modelling and problem solving - A cognitive apprenticeship approach to mathematics and engineering education," International Journal of Engineering Pedagogy, vol. 4, no. 5, pp. 49-55, 2014. https://doi.org/10.3991/ ijep.v4i5.3555

[30] W. Schneider and C. Artelt, "Metacognition and mathematics education," ZDM International Journal on Mathematics Education, 2010. https://doi.org/10.1007/s11858$\underline{010-0240-2}$

[31] M. A. Pappas, A. S. Drigas and F. Polychroni, "An eight-layer model for mathematical cognition," International Journal of Emerging Technologies in Learning, vol. 13, no. 10, pp. 69-82, 2018. https://doi.org/10.3991/ijet.v13i10.8633

[32] A. Whimbey and J. Lochhead, Problem Solving \& Comprehension, sixth edition. Philadelphia: The Franklin Institute Press, 2013.

[33] R. Lesh and H. M. Doerr, "Foundations of a models and modeling perspective on mathematics teaching, learning, and problem solving," in Beyond constructivism: Models and modeling perspectives on mathematics problem solving, learning, and teaching, R. Lesh and H. M. Doerr, Eds. Mahwah, NJ: Lawrence Erlbaum Associates, 2003, pp. 3-33. https://doi.org/10.1007/978-0-387-29822-1_15 
[34] R. Lesh, M. Hoover, A. Kelly, and T. Post, "Principles for developing thought-revealing activities for students andteachers," in Research Design in Mathematics and Science Education, A. Kelly and R. Lesh, Eds. Mahwah, New Jersey: Lawrence Erlbaum Associates, 2000, pp. 591--7646.

[35] R. Borromeo Ferri, Learning how to Teach Mathematical Modeling in School and Teacher Education. New York: Springer, 2018. https://doi.org/10.1007/978-3-319-68072-9

[36] S. M. Brookhart, How to Assess Higher Order Thinking Skills in Your Classroom. Alexandria, VA: ASCD, 2010.Result score too low.

[37] D. R. Krathwohl, “A revision of Bloom's taxonomy: An overview,” Theory Into Practice, vol. 41, no. 4, pp. 212-218, 2002. https://doi.org/10.1207/s15430421tip4104 2

[38] P. Tamminen and J. Moilanen, "Design revolution in 3D printing processes," in Consilence and Innovation in Design, 2013, pp. 1165-1176.

[39] A. Goriely, Applied Mathematics: A Very Short Introduction. Oxford University Press, 2018.

[40] S. S. Guzey, M. Harwell, M. Moreno, Y. Peralta, and T. J. Moore, "The impact of designbased STEM integration curricula on student achievement in engineering, science, and mathematics," Journal of Science Education and Technology, vol. 26, no. 2, pp. 207-222, 2017. https://doi.org/10.1007/s10956-016-9673-x

[41] S. M. Gomez Puente, M. V. van Eijck, and W. Jochems, "Towards characterising designbased learning in engineering education: A review of the literature," European Journal of Engineering Education, vol. 36, no. 2, pp. 137-149, 2011. https://doi.org/10.1080/ $\underline{03043797.2011 .565116}$

[42] M. Lammi and K. Becker, "Engineering design thinking," Journal of Technology Education, vol. 24, no. 2, pp. 55-77, 2013.

[43] W. X. Zhang, Y. S. Hsu, C. Y. Wang, and Y. T. Ho, "Exploring the impacts of cognitive and metacognitive prompting on students' scientific inquiry practices within an E-learning environment," International Journal of Science Education, 2015. https://doi.org/10.1080/ $\underline{09500693.2014 .996796}$

[44] B. Hoffman and A. Spatariu, "The influence of self-efficacy and metacognitive prompting on math problem-solving efficiency," Contemporary Educational Psychology, 2008. https://doi.org/10.1016/j.cedpsych.2007.07.002

\section{Authors}

Laura Levin is a $\mathrm{PhD}$ student at the Faculty of Education in Science and Technology, Technion - Israel Institute of Technology, Technion City, Haifa, 3200003, Israel. She is founder and director of the Alon Foundation for Education, a philanthropic project that promotes innovative and active learning through the integration of 3D printing. Email: laura-1@campus.technion.ac.il

Igor Verner is Professor of the Faculty of Education in Science and Technology at the Technion - Israel Institute of Technology, Technion City, Haifa, 3200003, Israel. $\mathrm{He}$ is Head of the Center for Robotics and Digital Technology Education and has minor affiliation at the Faculty of Industrial Engineering and Management.

This article is a revised version of a paper presented at the EDUCON2020 conference held virtually in Porto, Portugal, 27-30 April 2020. Article submitted 2020-11-18. Resubmitted 2021-03-16. Final acceptance 2021-03-17. Final version published as submitted by the authors. 